\title{
Effects of Arginine Supplementation on Organ Development, Egg Quality, Serum Biochemical parameters, and Immune Status of Laying Hens
}

-Author(s)

$$
\begin{aligned}
& \text { Yang } H^{\prime} \\
& \text { Ju X' } \\
& \text { Wang Z' } \\
& \text { Yang Z' } \\
& \text { Lu J" } \\
& \text { Wang W' }
\end{aligned}
$$

College of Animal Science and Technology, Yangzhou University, Yangzhou, Jiangsu Province, P.R. China, 225009;

" Poultry Institute, Chinese Academy of Agricultural Sciences, Yangzhou, Jiangsu Province, P.R. China, 225009

\section{-Mail Address}

Corresponding author e-mail address

Dr. Haiming Yang (Associate Prof. in Poultry Nutrition and Production)

East Wenhui Road 48\#, Yangzhou, 225009

Jiangsu Province, People's Republic of China.

Phone: $\quad+8651487979045$

Fax: $\quad+8651487990256$

E-mail: yhmdlp@qq.com

\section{-Keywords}

Arginine, clinical blood parameters, immune status, laying hens, organs development.

\section{ABSTRACT}

This experiment was conducted to study the effects of arginine supplementation on organ development, egg quality, blood parameters, and immune status of laying hens. A total of 36025 -week-old brown Leghorn laying hens were randomly divided into three groups with six replicates of 20 birds each and fed diets supplemented with $0,8.5$, or $17 \mathrm{mg}$ of L-arginine/kg for 42 days. Results showed that the weight of proventriculus and duodenum in the treatment supplemented with 17 $\mathrm{mg} / \mathrm{kg} \mathrm{L}$-arginine was heavier than that of $0 \mathrm{mg} \mathrm{L}$-arginine $/ \mathrm{kg}$ treatment $(p<0.05)$. The weight of oviduct in the treatments supplemented with $17 \mathrm{mg} / \mathrm{kg} \mathrm{L}$-arginine was smaller than that of 0 and $8.5 \mathrm{mg} \mathrm{L}$-arginine/ $\mathrm{kg}$ treatment $(p<0.05)$, and the small yellow follicle amount in the treatment supplemented with $17 \mathrm{mg} / \mathrm{kg} \mathrm{L}$-arginine was less than that of $0 \mathrm{mg} \mathrm{L}$-arginine $/ \mathrm{kg}$ treatment $(p<0.05)$, while its yolk color was deeper than that of $0 \mathrm{mg} \mathrm{L}$-arginine/kg treatment $(p<0.05)$, and the $\lg Y$ content showed the same tendency. Total cholesterol and triglyceride levels in the treatment supplemented with $8.5 \mathrm{mg} / \mathrm{kg} \mathrm{L}$-arginine were lower than that of $0 \mathrm{mg} \mathrm{L}$-arginine $/ \mathrm{kg}$ treatment $(p<0.05)$. The concentration of IL-2 in the treatment supplemented with $17 \mathrm{mg} /$ $\mathrm{kg} \mathrm{L}$-arginine were more than that of $0 \mathrm{mg} \mathrm{L}$-arginine $/ \mathrm{kg}$ treatment $(p<0.05)$. The findings of this study show that $17 \mathrm{mg} / \mathrm{kg} \mathrm{L}$-arginine supplementation has beneficial effects onlayers' immune status and yolk IgY content, as well as on proventriculus and duodenum weight while no adverse effects were observed on laying performance, egg quality, or blood parameters.

\section{INTRODUCTION}

Arginine (Arg), a ubiquitous basic amino acid, is necessary for maintenance, growth, reproduction, and immunity (Wu, 2009). Poultry are not able to synthesize arginine themselves, and therefore completely depend on dietary arginine to meet their arginine needs for protein synthesis and other functions (D'Mello \& Lewis, 1971). In addition, arginine becomes the most important amino acid when lysine is adequate in diet. Arginine plays a vital role in the modulation of protective immune response (Tayade et al., 2006), and it is an important substrate for the immune system (Amato \&Humphrey, 2010). Cengiz et al. (2010) found that Arg supplementation reduced proteinemia, and modified erythrocyte characteristics, increasing their mean volume and reducing mean corpuscular hemoglobin load.

In 2010, Khajali \& Wideman considered that the arginine recommendations of the NRC might not be adequate to support maximal growth and arginine-depleting immune responses, and to prevent the onset of pulmonary hypertension in broilers reared under rigorous environmental conditions. Perez-Carbajal et al. (2010) found that arginine fed at levels higher than those recommended by the NRC 


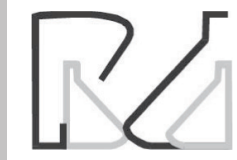

could play a complementary role in the innate and humoral immune responses, potentially enhancing the immune response to field infections.

Although there are many studies in literature on arginine in broilers, few studies were found in laying hens. Therefore, it makes sense to study the effect of arginine on the performance and immune status of laying hens. The objective of the present study was to establish the effect of arginine on laying performance, egg quality, organ development, blood parameters, and immune status of laying hens. http://ps.fass.org/ content/89/9/1870 - aff-3\#aff-3

\section{MATERIALS AND METHODS}

\section{Experiment Design}

The experiment was carried out in the facilities of Jinghu Yongxiang breeding hens Co., LTD,. Huaian, Jiangsu Province, China. Three hundred and sixty 25-week-old brown Leghorn laying hens were randomly divided into three treatments with six replicates of 20 birds each (120 laying hens per group). The birds were fed diets supplemented with $0 \mathrm{mg} / \mathrm{kg}$, $8.5 \mathrm{mg} / \mathrm{kg}$, or $17 \mathrm{mg} / \mathrm{kg}$ of L-arginine for 42 days. Hens were maintained in a layer house with tiled roof at a density of two birds per battery cage $(50 \times 50 \mathrm{~cm})$. The photoperiod was set at 16L:8D throughout the study. Housing temperature and relative humidity, controlled by automatic system, were kept at $25-29^{\circ} \mathrm{C}$ and $65-$ $75 \%$, respectively. Water and feed were provided ad libitum during the study in automatic trough drinkers and feeders, respectively. Egg production was recorded daily, and the laying ratio was calculated by using whole egg production dividing feeding days.

Table 1 presents the composition of the experimental diets. All animal handing protocols were approved by of the Animal Care and Use Committee of the University.

Table 1 - Composition and nutrient levels of the diet (airdried basis) \%

\begin{tabular}{llll}
\hline Ingredients & Content & Nutrient levels & Content \\
\hline Corn & 62.5 & ME/(MJ/kg) & 11.91 \\
Soybean meal & 16.2 & Crude Protein & 16.02 \\
Corn gluten meal & 6.0 & Calcium & 3.75 \\
Limestone & 8.0 & Available Phosphorus & 0.40 \\
Soybean oil & 2.3 & Arginine & 0.87 \\
Premix $^{1 \otimes}$ & 5.0 & & \\
Total & 100.0 & & \\
\hline
\end{tabular}

'The premix provided the following per kg of the diet, Vit. A 12,500 IU, Vit. D 4, 125 IU, Vit. E 15 IU, Vit. K 2 mg, thiamine $1 \mathrm{mg}$, riboflavin $8.5 \mathrm{mg}$, calcium pantothenate 50 $\mathrm{mg}$, nicotinic acid $32.5 \mathrm{mg}$, pyridoxine $8 \mathrm{mg}, V_{12} 5 \mathrm{mg}$, biotin $2 \mathrm{mg}$, Fe $60 \mathrm{mg}$, Cu 8 mg, Zn 66 mg, Mn 65 mg, Se 0.3 mg, I 1 mg.

${ }^{2}$ Nutrient levels were all measured values.
Effects of Arginine Supplementation on Organ Development, Egg Quality, Serum Biochemical parameters, and Immune Status of Laying Hens

\section{Blood Parameters}

At the end of the 42-day feeding period, blood samples $(2.5 \mathrm{~mL})$ were collected from the wing vein of 54 birds (three birds per replicate, 18 birds per treatment) for blood chemistry. Blood samples centrifuged at $3500 \mathrm{~g}$ for $10 \mathrm{~min}$, and the following parameters were determined in the serum: total protein (TP), albumin (ALB), aspartate aminotransferase (AST), total cholesterol, and triglyceride levels. All parameters were measured using a biochemical analyzer (UniCel DxC 800 Synchron, Beckman coulter, USA).

\section{Organ Development}

After the collection of blood samples, all the birds were killed by exsanguination. The following organs were weighed (paired organs were weighed together): proventriculus, gizzard, heart, liver, spleen, duodenum, jejunum, ileum, cecum, rectum, oviduct, ovarium, and follicle. In addition, oviduct length, and number of preovulatory follicles amount, of small yellow follicles, and of large white follicle amounts were also determined.

\section{Egg Quality}

Eighteen eggs per treatment ( 3 eggs per replicate) were collected at the end of the study to determine egg quality parameters. Egg shape index was calculated according to the formula: shape index = height/width (Anderson et al., 2004). Eggs were weighed and the shell strength of intact eggs was measured with an Instron testing machine (TSS, York, UK.). A constantly increasing load was applied to an egg lying lengthways until it broke. The applied load at the time of breakage is the measured shell strength. Eggs were cracked onto a flat surface, and the height of the albumen was measured using a digital albumen height gauge (TSS, York, UK). The measurement was taken at three points of the thick and flat albumen in the $1-\mathrm{cm}$ diameter area around the egg yolk, forming an equilateral triangle. After separated from the albumen, the yolk was weighed. Albumen mass was calculated as the difference between egg weight and the sum of yolk and eggshell weights, and expressed as a percentage of egg weight. Yolk color was evaluated with DSM Yolk Color Fan, which included 15 colorimetric blades according to their intensity of yellow (QCC-System, TSS), and expressed in grades. Eggshell thickness was the mean value of the measurements made at three different locations (air cell, equator, and sharp end), and determined in the fresh shell without membranes by a digital micrometer (TSS). 
In addition, all the egg yolks were frozen at $-20^{\circ} \mathrm{C}$ for IgY analysis. The concentration of yolk IgY was measured according to a commercial Chicken IgY ELISA Quantitation Kit provided by Nanjing jiancheng Co. (Nanjing, China).

\section{Immune Status}

The blood concentrations of interleukin-2 (IL-2) and interferon- $\gamma$ (IFN- $\gamma$ ) were measured using an enzymelinked immuno sorbent assay-based method according to Dalloul et al. (2003).

\section{Statistical Analysis}

All data were subjected to repeated measure analysis, using the mean of each replicate as the experimental unit. All data were analyzed using SPSS software (SPSS 17.0 for windows). One-way analysis of variance, followed by a Duncan's multiple comparison test, were applied to separate different means among treatments. Data were assumed to be statistically significant when $p<0.05$.

\section{RESULTS}

\section{Blood Parameters}

Total serum cholesterol and triglyceride levels of the hens in the treatment supplemented with $8.5 \mathrm{mg} /$ $\mathrm{kg} \mathrm{L}$-arginine were lower than those of hens in the 0 $\mathrm{mg} \mathrm{L}$-arginine/kg treatment $(\mathrm{p}<0.05$, Table 2$)$. There were no effects of dietary arginine supplementation on serum TP, ALB, or AST levels ( $p>0.05$ ).

Table 2 - Effects of arginine on blood parameters

\begin{tabular}{llll}
\hline \multirow{2}{*}{ Items } & \multicolumn{3}{c}{ Arginine $(\mathrm{mg} / \mathrm{kg})$} \\
\cline { 2 - 4 } & 0 & 8.5 & 17 \\
\hline $\operatorname{TP}(\mathrm{g} / \mathrm{L})$ & $35.14 \pm 1.21$ & $34.84 \pm 0.94$ & $34.90 \pm 0.52$ \\
ALB $(\mathrm{g} / \mathrm{L})$ & $21.98 \pm 0.40$ & $21.97 \pm 0.33$ & $21.96 \pm 1.17$ \\
AST $(\mathrm{U} / \mathrm{L})$ & $208.27 \pm 10.31$ & $213.20 \pm 9.19$ & $202.44 \pm 5.86$ \\
$\begin{array}{l}\text { Total cholesterol/ } \\
\text { (mmol/L) }\end{array}$ & $3.82^{\mathrm{a}} \pm 0.29$ & $3.12^{\mathrm{b}} \pm 0.21$ & $3.26^{\mathrm{ab}} \pm 0.15$ \\
$\begin{array}{l}\text { Triglyceride/ } \\
\text { (mmol/L) }\end{array}$ & $11.35^{\mathrm{a}} \pm 0.80$ & $8.90^{\mathrm{b}} \pm 0.86$ & $10.07^{\mathrm{ab}} \pm 0.69$ \\
\hline
\end{tabular}

$\mathrm{a}, \mathrm{b} M e a n \pm \mathrm{SE}$ with different superscripts within a column are significantly different $(p<0.05)$.

\section{Organ Development}

Proventriculus weight of the hens in the treatment supplemented with $17 \mathrm{mg} / \mathrm{kg}$ L-arginine was heavier compared with the $0 \mathrm{mg} \mathrm{L}$-arginine/ $\mathrm{kg}$ treatment $(p<0.05$, Table 3). Duodenum weight of the hens in the treatments supplemented with 8.5 and $17 \mathrm{mg} /$ $\mathrm{kg} \mathrm{L}$-arginine was heavier than that of hens fed $0 \mathrm{mg}$ $\mathrm{L}$-arginine/kg $(p<0.05)$. There were no differences in the weight of body, gizzard, heart, liver, spleen, jejunum, ileum, cecum and rectum among the treatments (p>0.05).

Table 3 - Effects of arginine on digestive tract development

\begin{tabular}{llll}
\hline \multirow{2}{*}{ Items } & \multicolumn{3}{c}{ Arginine $(\mathrm{mg} / \mathrm{kg})$} \\
\cline { 2 - 4 } & 0 & 8.5 & 17 \\
\hline Proventriculus weight $(\mathrm{g})$ & $5.46^{\mathrm{a}} \pm 0.18$ & $5.74^{\mathrm{ab}} \pm 0.14$ & $6.23^{\mathrm{b}} \pm 0.27$ \\
\hline Gizzard weight $(\mathrm{g})$ & $22.69 \pm 0.61$ & $22.72 \pm 0.49$ & $23.85 \pm 0.48$ \\
\hline Heart weight $(\mathrm{g})$ & $6.10 \pm 0.16$ & $5.85 \pm 0.20$ & $5.91 \pm 0.18$ \\
Liver weight $(\mathrm{g})$ & $26.73 \pm 0.99$ & $27.62 \pm 0.99$ & $28.13 \pm 0.77$ \\
Spleen weight $(\mathrm{g})$ & $1.62 \pm 0.10$ & $1.77 \pm 0.11$ & $1.90 \pm 0.13$ \\
Duodenum weight $(\mathrm{g})$ & $6.72^{\mathrm{a}} \pm 0.20$ & $7.41^{\mathrm{b}} \pm 0.26$ & $7.52^{\mathrm{b}} \pm 0.23$ \\
Jejunum weight (g) & $13.26 \pm 0.44$ & $13.05 \pm 0.54$ & $13.71 \pm 0.54$ \\
lleum weight (g) & $9.28 \pm 0.28$ & $9.35 \pm 0.32$ & $9.02 \pm 0.35$ \\
Cecum weight (g) & $5.38 \pm 0.15$ & $5.59 \pm 0.21$ & $5.65 \pm 0.16$ \\
Rectum weight (g) & $3.28 \pm 0.17$ & $3.19 \pm 0.15$ & $3.44 \pm 0.16$ \\
\hline
\end{tabular}

a,b Mean \pm SE with different superscripts within a column are significantly different $(p<0.05)$.

\section{Reproductive Organ Development}

Oviduct weight of the hens in the treatment supplemented with $17 \mathrm{mg} / \mathrm{kg}$ L-arginine was lighter than that of those fed 0 and $8.5 \mathrm{mg} \mathrm{L}$-arginine/ $\mathrm{kg}$ treatment $(p<0.05$, Table 4$)$. The number of small yellow follicles of the hens supplemented with $17 \mathrm{mg} /$ $\mathrm{kg} \mathrm{L}$-arginine was lower than that of the hens fed 0 $\mathrm{mg} \mathrm{L}$-arginine/kg $(p<0.05)$. There were no differences among treatments in oviduct length, weights of ovary and follicles, preovulatory follicle number and number of big white follicles $p>0.05$ ).

Table 4 - Effects of arginine on reproductive organ development

\begin{tabular}{llll}
\hline & \multicolumn{3}{c}{ Arginine $(\mathrm{mg} / \mathrm{kg})$} \\
\cline { 2 - 4 } Items & 0 & 8.5 & 17 \\
\hline Oviduct weight $(\mathrm{g})$ & $54.06^{\mathrm{a}} \pm 1.84$ & $54.89^{\mathrm{a}} \pm 2.11$ & $47.86^{\mathrm{b}} \pm 1.27$ \\
\hline Oviduct length $(\mathrm{cm})$ & $56.56 \pm 1.09$ & $58.90 \pm 1.29$ & $56.15 \pm 0.90$ \\
\hline Ovarium weight $(\mathrm{g})$ & $4.33 \pm 0.22$ & $4.52 \pm 0.19$ & $4.78 \pm 0.25$ \\
\hline $\begin{array}{llll}\text { Follicle weight }(\mathrm{g}) \\
\text { Number of follicles }\end{array}$ & $27.42 \pm 1.35$ & $26.57 \pm 1.77$ & $27.95 \pm 1.75$ \\
$\begin{array}{l}\text { Number of } \\
\text { preovulatory follicles }\end{array}$ & $4.00 \pm 0.34$ & $4.00 \pm 0.21$ & $4.12 \pm 0.15$ \\
$\begin{array}{l}\text { Number of } \\
\text { small yellow follicles }\end{array}$ & $6.31^{\mathrm{a}} \pm 0.86$ & $5.14^{\mathrm{ab}} \pm 0.50$ & $4.06^{\mathrm{b}} \pm 0.56$ \\
$\begin{array}{l}\text { Number of } \\
\text { large white follicles }\end{array}$ & $8.38 \pm 1.06$ & $8.43 \pm 0.95$ & $9.40 \pm 0.94$ \\
\hline
\end{tabular}

a,bMean \pm SE with different superscripts within a column are significantly different $(p<0.05)$.

\section{Egg Quality}

The yolk color of the eggs of the hens supplemented with $17 \mathrm{mg} / \mathrm{kg} \mathrm{L}$-arginine was deeper than those of hens fed $0 \mathrm{mg} \mathrm{L}$-arginine $/ \mathrm{kg}(\mathrm{p}<0.05$, Table 5$)$. The laying ratio and the other egg quality parameters measured were unaffected by dietary arginine ( $p>0.05)$. 


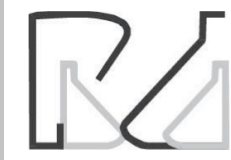

Table 5 - Effects of arginine on performance and egg quality

\begin{tabular}{llll}
\hline \multirow{2}{*}{ Items } & \multicolumn{3}{c}{ Arginine $(\mathrm{mg} / \mathrm{kg})$} \\
\cline { 2 - 4 } & 0 & 8.5 & 17 \\
\hline Laying ratio (\%) & $91.38 \pm 0.86$ & $90.51 \pm 0.20$ & $89.61 \pm 0.47$ \\
Average egg weight $(\mathrm{g})$ & $53.44 \pm 0.13$ & $52.86 \pm 0.30$ & $52.78 \pm 0.43$ \\
Shape index of egg & $1.28 \pm 0.01$ & $1.27 \pm 0.01$ & $1.29 \pm 0.01$ \\
Eggshell strength $\left(\mathrm{kg} / \mathrm{cm}^{2}\right)$ & $4739 \pm 136$ & $4821 \pm 174$ & $4654 \pm 196$ \\
\hline Eggshell thickness $(\mathrm{mm})$ & $0.32 \pm 0.01$ & $0.31 \pm 0.00$ & $0.30 \pm 0.01$ \\
Albumen height $(\mathrm{mm})$ & $6.11 \pm 0.16$ & $6.29 \pm 0.17$ & $6.53 \pm 0.24$ \\
Eggshell weight $(\mathrm{g})$ & $7.08 \pm 0.15$ & $6.81 \pm 0.12$ & $6.92 \pm 0.17$ \\
Yolk weight $(\mathrm{g})$ & $12.12 \pm 0.19$ & $12.71 \pm 0.29$ & $12.17 \pm 0.25$ \\
Yolk color & $8.19^{\mathrm{a}} \pm 0.19$ & $8.63^{\mathrm{ab}} \pm 0.15$ & $8.94{ }^{\mathrm{b}} \pm 0.17$ \\
\hline
\end{tabular}

$a, b$ Mean \pm SE with different superscripts within a column are significantly different $(p<0.05)$.

\section{Immune Status}

The IgY content change showed the same tendency, and the $\lg Y$ content of the eggs of the hens supplemented with $17 \mathrm{mg} / \mathrm{kg}$ L-arginine was $62.8 \%$ higher compared with those laid by the hens in the 0 $\mathrm{mg} \mathrm{L}$-arginine/kg treatment. The concentration of IL-2 in the eggs of the hens fed $17 \mathrm{mg} / \mathrm{kg} \mathrm{L}$-arginine were $41.8 \%$ higher compared with the eggs of the hens in the $0 \mathrm{mg} \mathrm{L}$-arginine/kg treatment $(p<0.05$, Table 6$)$.

Table 6 - Effects of arginine on immune status

\begin{tabular}{llll}
\hline \multirow{2}{*}{ Items } & \multicolumn{3}{c}{ Arginine $(\mathrm{mg} / \mathrm{kg})$} \\
\cline { 2 - 4 } & 0 & 8.5 & 17 \\
\hline IgY content $(\mu \mathrm{g})$ & $90.92^{\mathrm{a}} \pm 10.53$ & $104.42^{\mathrm{ab}} \pm 8.71$ & $148.02^{\mathrm{b}} \pm 35.14$ \\
\hline $\mathrm{IL}-2(\mathrm{ng} / \mathrm{L})$ & $3.85^{\mathrm{a}} \pm 0.37$ & $4.31^{\mathrm{ab}} \pm 0.38$ & $5.46^{\mathrm{b}} \pm 0.69$ \\
IFN- $(\mathrm{ng} / \mathrm{L})$ & $60.81 \pm 6.49$ & $68.70 \pm 6.86$ & $79.02 \pm 9.76$ \\
\hline
\end{tabular}

a,bMean \pm SE with different superscripts within a column are significantly different $(p<0.05)$.

\section{DISCUSSION}

\section{Blood Parameter}

In the present experiment, total cholesterol and triglyceride serum levels in the hens supplemented with $8.5 \mathrm{mg} / \mathrm{kg} \mathrm{L}$-arginine was lower than that of 0 $\mathrm{mg} \mathrm{L}$-arginine/kg treatment, which was in accordance with many previous results (Fouad et al., 2013; Ueda et al., 1995; Al-Daraji et al., 2012). Fouad et al. (2013) and Ueda et al. (1995) found that dietary arginine supplementation significantly decreased blood serum cholesterol. Al-Daraji et al. (2012) found that the dietary arginine supplementation significantly decreased blood total lipids and triglyceride concentrations.

\section{Organ Development}

Arginine supplementation had a weak influence on organ weight. Cengiz \& Kucukersan (2010) did not find any significant differences in the carcass
Effects of Arginine Supplementation on Organ Development, Egg Quality, Serum Biochemical parameters, and Immune Status of Laying Hens

traits of broilers fed diets supplemented with arginine or not. Leitgeb et al. (2004) also verified that broiler organ weight, carcass chemical composition, and meat quality (tenderness, juiciness and taste) were not influenced by the dietary supplementation of with different levels of arginine. Jahanian (2009) found that dietary arginine deficiency affected the thymus and the spleen of broilers. However, all the above studies were performed with broilers, and few studies concerning on arginine in laying hens were published. In this study, there were no significant differences in viscera weights except for the proventriculus and duodenum. How these two organs were stimulated to develop much heavier? Was arginine the reason? Further research is needed to elucidate the mechanisms of this phenomenon.

\section{Reproductive Organ Development and Egg Quality}

Arginine supplementation reduced oviduct weight and the number of small yellow follicles, while it had no significant influence on the other reproductive organs. Even though the number of small yellow follicles in the treatment supplemented with $17 \mathrm{mg} / \mathrm{kg} \mathrm{L}$-arginine was lower than with that in the control group, the number of preovulatory follicles was not different. This may explained by a higher apoptosis rated of small yellow follicles in hens supplemented with $17 \mathrm{mg} / \mathrm{kg}$ L-arginine compared with the control group.

The yolk color and IgY content of the eggs from hens supplemented with $17 \mathrm{mg} / \mathrm{kg}$ L-arginine increased compared with that in the control group, which may explained by the promotion of lutein and IgY deposition by dietary arginine. In this experiment, daily feed intake and laying ratio were $120 \mathrm{~g}$ and $90 \%$, respectively, and consequently, $2.04 \mathrm{mg}$ dietary arginine supplementation resulted in about $57 \mu \mathrm{g} \lg Y$ in the egg. Therefore, it was an effective method to produce a functional egg containing large quantities of IgY, which could be used to prevent diseases.

\section{Immune Status}

In this experiment, dietary arginine supplementation increased the serum concentration of IL-2. Arginine supplementation may enhance the immune status of animals. Cengiz \& Kucukersan (2010) found that arginine promoted non-specific immunity with monocyte expansion. Arginine supplementation stimulates the functional activities of different cell types, including natural-killer cells, and the systemic immune response against IBDV in chickens (Tayade et al., 2006) 
and anti-BSA (bovine serum albumin) IgM levels in lying hens (Deng et al., 2005). In addition, arginine may improve local wound healing by decreasing the inflammatory response at the wound site (Angele et al., 2002).

The duration and amount of arginine supplementation may influence immune status. Deng et al. (2005) found that short-term supplementary arginine had minimal effects on immunity, but some enhancement of SRBC antibody responses in later stages of growth was observed with previous arginine administration. In addition, a study found minimal effects of arginine supplementation on broiler growth and immune parameters (Kidd et al., 2001), possibly because the levels of arginine supplementation were low. On the other hand, the proportion of heterophils in peripheral blood was reduced in broiler chicks fed Argdeficient diets (Jahanian, 2009). Moreover, a decrease in dietary crude protein and Arg levels diminished the antibody production response to Newcastle disease virus (Jahanian, 2009), suggesting that a minimal level of arginine needs to be supplied in poultry diets.

In conclusion, the findings of this study show that the supplementation of $17 \mathrm{mg} / \mathrm{kg} \mathrm{L}$-arginine to layer diets benefits their immune status and increases yolk IgY content, as well as promotes heavier proventriculus and duodenum, while no adverse effects are observed on laying performance, egg quality, or blood parameters.

\section{ACKNOWLEDGMENTS}

This research was financially supported by the Support Project of Natural Science of Jiangsu Province (NO. BK2012685), and the Key research and development program (modern agriculture) of Huaian Sity (HAN2015012).

\section{REFERENCES}

Al-Daraji HJ, Al-Mashadani AA, Al-Hayani WK, Al-Hassani AS, Mirza $H A$. Effect of in ovo injection with L-arginine on productive and physiological traits of Japanese quail. South African Journal of Animal Science 2012;42(2):139-145

Amato $\mathrm{JL}$, Humphrey BD. Dietary arginine levels alter markers of arginine utilization in peripheral blood mononuclear cells and thymocytes in young broiler chicks. Poultry Science 2010;89(5):938-947.

Anderson KE, Tharrington JB, Curtis PA, Jones FT. Shell characteristics of eggs from historic strains of single comb white leghorn chickens and relationship of egg shape to shell strength. International Journal of Poultry Science 2004;3(1):17-19.

Angele MK, Nitsch SM, Hatz RA, Angele P, Hernandez-Richter T, Wichmann $M W$, et al. L-Arginine: A unique amino acid for improving depressed wound immune function following hemorrhage. European Surgical Research 2002;34(1-2):53-60

Cengiz O, Kucukersan S. Effects of graded contents of arginine supplementation on growth performance, haematological parameters and immune system in broilers. Reviews in Medical Veterinaire 2010;161(8-9):409-417

Dalloul RA, Lillehoj HS, Shellem TA, Doerr JA. Intestinal immunomodulation by vitamin A deficiency and Lactobacillus-based probiotic in Eimeria acervulina-infected broiler chickens. Avian Diseases 2003;47(4):13131320.

Deng K, Wong CW, Nolan JV. Long-term effects of early life L-arginine supplementation on growth performance, lymphoid organs and immune responses in Leghorn-type chickens. British Poultry Science 2005;46(3):318-324.

D'Mello JP, Lewis D. Amino acid interactions in chick nutrition. 4. Growth, food intake and plasma amino acid patterns. British Poultry Science $1971 ; 12(3): 345-358$.

Fouad AM, El-Senousey HK, Yang XJ, Yao JH. Dietary L-arginine supplementation reduces abdominal fat content by modulating lipid metabolism in broiler chickens. Animal 2013;7(8):1239-1245.

Jahanian R. Immunological responses as affected by dietary protein and arginine concentrations in starting broiler chicks. Poultry Science 2009;88(9):1818-1824.

Khajali F, Wideman RF. Dietary arginine: metabolic, environmental, immunological and physiological interrelationships. World's Poultry Science Journal 2010;66(4):751-765

Kidd MT, Peebles ED, Whitmarsh SK, Yeatman JB, Wideman RF Jr. Growth and immunity of broiler chicks as affected by dietary arginine. Poultry Science 2001;80(11):1535-1542

Latshaw JD, Zhao L. Dietary protein effects on hen performance and nitrogen excretion. Poultry Science 2011;90(1):99-106

Leitgeb R, Tschischej M, Hutterer E, Bartelt J.Impact of protein reduction and arginine and valine supplementation in the diet on growth and slaughter performance of broilers. Bodenkultur 2004;54:187-195.

Miyazaki $Y$, Takahashi $K$, Akiba $Y$. Developmental changes in mRNA expression in immune-associated cells of intestinal tract of broiler chickens after hatch and by dietary modification. Animal Science of Journal 2007;78(5):527-534.

NRC - National Research Council. Nutrient requirements of poultry. 9th rev. ed. Washington: National Academy Press; 1994.

Perez-Carbajal C, Caldwell D, Farnell M. Immune response of broiler chickens fed different levels of arginine and vitamin $\mathrm{E}$ to a coccidiosis vaccine and Eimeria challenge. Poultry Science 2010;89(9):1870-1877.

Tayade C, Jaiswal TN, Mishra SC, Koti M. L-Arginine stimulates immune response in chickens immunized with intermediate plus strain of infectious bursal disease vaccine. Vaccine 2006;24(5):552-560

Tayade C, Koti1 M, Mishra SC. L-Arginine stimulates intestinal intraepithelial lymphocyte functions and immune response in chickens orally immunized with live intermediate plus strain of infectious bursal disease vaccine. Vaccine 2006;24(26):5473-5480.

Ueda H, Imanishi T, Fukumi R, Kumai S.Effect of dietary lysine and arginine addition on growth performance and serum cholesterol level in chicks. Animal Science and Technology 1995;63:1032-1037.

Wu GY. Amino acids: metabolism, functions, and nutrition. Amino Acids 2009:37(1):1-17. 
